\title{
Aortic root translocation (Nikaidoh procedure): Intermediate follow-up and impact of conduit type
}

\author{
Vijayakumar Raju, MD, ${ }^{\mathrm{a}}$ Patrick O. Myers, MD, ${ }^{\mathrm{a}, \mathrm{b}}$ Luis G. Quinonez, MD, ${ }^{\mathrm{a}}$ Sitaram M. Emani, MD, ${ }^{\mathrm{a}}$ \\ John E. Mayer, Jr, MD, ${ }^{a}$ Frank A. Pigula, MD, ${ }^{a}$ Pedro J. del Nido, MD, ${ }^{a}$ and Christopher W. Baird, MD $^{\mathrm{a}}$
}

Objective: Aortic root translocation is a promising surgical option for repair of transposition of the great arteries, ventricular septal defect, and pulmonary stenosis. There are little data on the outcomes of this procedure, with no long-term follow-up available. We reviewed our experience with aortic root translocation and the impact of the type of right ventricular outflow tract reconstruction.

Methods: The demographic, procedural, and outcome data were obtained for 32 patients who underwent aortic root translocation from 1997 to 2013 at Boston Children's Hospital. Patients were grouped on the basis of right ventricular outflow tract reconstruction with a valved conduit or a nonvalved anastomosis of the pulmonary artery bifurcation to the right ventricular outflow tract with anterior patch augmentation (transannular patch).

Results: The median age was 7.5 months (16 days to 42 years). Twenty-six patients had valved conduits, and 6 patients had transannular patches. There were no significant differences between groups in baseline and operative characteristics. There was 1 early death (transannular patch group). There were no late deaths during a median follow-up of 20.8 months ( 1 month to 16.5 years). No patients developed late left ventricular outflow tract obstruction. Transcatheter reintervention was required in 14 patients, 9 with valved conduits (34.6\%) and 1 with transannular patch $(20 \%, P>.99)$. Six patients $(19.4 \%)$ required reoperation, all with a valved conduit $(P=.34)$.

Conclusions: Aortic root translocation can be done with low early and late mortality. There was preserved aortic valve function and no left ventricular outflow tract obstruction at late follow-up. The use of a transannular patch had early outcomes comparable to valved conduits, with a trend for fewer late reoperations. (J Thorac Cardiovasc Surg 2015;149:1349-55)

See related commentary pages $1356-7$.

The ideal surgical option for the management of dextrotransposition of the great arteries (D-TGA) with ventricular septal defect (VSD) and pulmonary stenosis (PS) is not clear. The currently available surgical options include recruitment of the native left ventricular outflow tract (LVOT) and the arterial switch operation (ASO), ${ }^{1,2}$ or non-ASO procedures, including the Rastelli procedure, ${ }^{3,4}$ the "réparation à l'étage ventriculaire" (REV), ${ }^{5-7}$ and aortic root translocation (Nikaidoh). ${ }^{8}$ The presence of severe left ventricular outflow tract obstruction (LVOTO) excludes the ASO as a surgical option. ${ }^{1}$ Although results of the Rastelli procedure are encouraging, the long-term

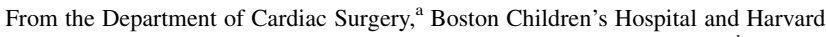
Medical School, Boston, Mass; and Division of Cardiovascular Surgery, ${ }^{\mathrm{b}}$ Geneva University Hospitals and School of Medicine, Geneva, Switzerland.

Disclosures: Authors have nothing to disclose with regard to commercial support.

Read at the 40th Annual Meeting of The Western Thoracic Surgical Association,

Dana Point, California, June 25-28, 2014.

Received for publication June 24, 2014; revisions received Oct 30, 2014; accepted for publication Nov 4, 2014; available ahead of print Dec 9, 2014

Address for reprints: Christopher W. Baird, MD, Department of Cardiac Surgery, Boston Children's Hospital, 300 Longwood Ave, Bader 273, Boston, MA 02115 (E-mail: christopher.baird@cardio.chboston.org).

$0022-5223 / \$ 36.00$

Copyright (c) 2015 by The American Association for Thoracic Surgery

http://dx.doi.org/10.1016/j.jtcvs.2014.11.014
}

outcomes are limited by the late development of left ventricular (LV) dysfunction, progressive development of LVOTO, and reoperations to change the right ventricle to pulmonary artery (RV-PA) conduit with associated risk of damage during sternal reentry, ${ }^{2,3}$ particularly because the ventriculotomy in the Rastelli procedure is closer to the midline. Aortic root translocation was first introduced by Bex and colleagues ${ }^{9}$ in 1980 and popularized by Nikai$\operatorname{doh}^{10}$ in 1984 as an alternative to REV or Rastelli repairs for transposition of the great arteries (TGA)/VSD/PS. The intermediate to midterm results of the Nikaidoh procedure appear superior to the Rastelli procedure in the late development of LVOTO, ${ }^{1,8,11-13}$ at the cost of higher technical complexity of the initial operation and longer operative times. The RV-PA conduit can be placed more laterally, potentially reducing the risk of re-sternotomy when it becomes necessary to change the RV-PA conduit. ${ }^{11}$

We previously reported our initial experience using the Nikaidoh procedure, which included 11 patients. ${ }^{11}$ The aim of this report is to review our more extensive experience with the Nikaidoh procedure and compare different options of managing the right ventricular outflow tract (RVOT).

\section{MATERIALS AND METHODS \\ Study Design}

This study is a retrospective review of all consecutive patients who underwent aortic root translocation (Nikaidoh procedure) at our institution 


$$
\begin{aligned}
& \text { Abbreviations and Acronyms } \\
& \text { ASO = arterial switch operation } \\
& \text { D-TGA }=\text { dextro-transposition of the great arteries } \\
& \mathrm{LV}=\text { left ventricular } \\
& \text { LVOT = left ventricular outflow tract } \\
& \text { LVOTO }=\text { left ventricular outflow tract obstruction } \\
& \text { PS = pulmonary stenosis } \\
& \text { REV = réparation à l'étage ventriculaire } \\
& \text { RVOT = right ventricular outflow tract } \\
& \text { RV-PA = right ventricle to pulmonary artery } \\
& \text { TGA }=\text { transposition of the great arteries } \\
& \text { VSD = ventricular septal defect }
\end{aligned}
$$

between 1997 and 2013. The demographic, procedural, and outcome data were obtained for all patients during the study period. The primary end points included mortality, transplantation, and RV-PA conduit reoperations during follow-up. Clinical or treatment variables were recorded to determine predictors of the outcome measures. The study was approved by the Boston Children's Hospital Institutional Review Board, and individual patient consent was waived.

\section{Surgical Technique}

The decision to perform aortic translocation is based on preoperative echocardiogram, cardiac catheterization in almost all patients, and magnetic resonance imaging in selected patients. Attention is focused on the cause of LVOTO and the conal septal anatomy. Patients with a pulmonary valve $Z$ score less than -3 with a large unrestrictive VSD are considered for aortic root translocation procedure.

After midline sternotomy, the aortic root is completely mobilized from the LVOT, roof of the left atrium, and the main and right pulmonary arteries. To avoid coronary kinking, the right coronary artery is skeletonized in its epicardial course from its origin to the right atrioventricular groove and a plane between the left anterior descending artery and RVOT is separated. All the dissection is done before giving heparin, if possible. If hemodynamic instability occurs during dissection, cardiopulmonary bypass is established with high aortic and bicaval cannulation. Myocardial protection is achieved by moderate hypothermia and del Nido potassiummagnesium-lidocaine cardioplegia. The aortic root is harvested from the RVOT similar to harvesting the pulmonary autograft in the Ross procedure, under a crossclamped aorta transected at the mid-ascending aorta. More recently, the aortic root is harvested without applying a crossclamp, using fibrillatory arrest, to keep the aortic root uncollapsed to help delineate the plane for harvesting the aortic root with intact coronaries, as well as to recognize coronary injury and possible coronary kinking earlier. If the coronary anatomy appears unfavorable, coronary buttons are harvested from the right coronary artery alone (partial coronary reimplantation) or both coronaries (full coronary reimplantation). Circular buttons are taken to preserve as much of the native sinotubular junction to avoid late aortic root dilatation.

Depending on the status of native pulmonary valve and annulus, the main pulmonary artery is preserved or completely divided at the valvular level. Any conal muscle causing LVOTO is divided. The VSD is enlarged if found to be restrictive. The aorta is crossclamped (if not done before) and transected at the level of the mid-ascending aorta. The harvested aortic root is moved posteriorly. If the coronary arteries were harvested, the optimal position of the aortic root is determined, using rotation if necessary and appropriate to the coronary anatomy (eg, none with intact coronaries, a $180^{\circ}$ rotation with full coronary reimplantation, or a variable amount with partial coronary reimplantation), and the coronary buttons are reimplanted. The LeCompte maneuver is performed, and the aortic anastomosis is completed. The VSD is closed using glutaraldehydetreated pericardium or a Dacron patch. The superior margin VSD patch sutures essentially run on the anterior suture line of aortic root. The RVOT is managed with RV-PA conduit using a valved homograft in younger infants or a nonvalved transannular patch in older children. To reduce the total cardiopulmonary bypass time and aortic crossclamp time, any additional procedures that do not involve the ascending aorta and root are usually performed using fibrillatory arrest before crossclamping the aorta. The patient is gradually weaned from cardiopulmonary bypass with help of a left atrial line, minimal inotropic support, and nitroglycerin. The adequacy of repair, including both ventricular function and regional wall motion abnormalities, is verified by transesophageal echocardiography, and the electrocardiogram is carefully observed for any ST-segment changes. Because the RV-PA conduit stays well away from the midline in aortic root translocation, an attempt for primary chest closure is made in most patients.

\section{Statistical Analysis}

Statistical analyses were performed with SPSS version 21 (SPSS Inc, Chicago, Ill). Data are presented as mean \pm standard deviation or median (range) where appropriate. Continuous variables were analyzed with the Student $t$ test, or the related samples Wilcoxon signed-rank test when appropriate, and categoric variables were analyzed using the chi-square test or Fisher exact test. Actuarial estimates were calculated using the Kaplan-Meier method, and differences between curves were assessed by the log-rank test. All statistical tests were 2-tailed.

\section{RESULTS \\ Demographics}

A total of 32 patients were included during the study period, with a median age of 7.5 months (range, 1 month to 42 years) and a median weight of $7.7 \mathrm{~kg}$ (range, 2.1$48.8 \mathrm{~kg}$ ). The baseline patient characteristics are summarized in Table 1. D-TGA with VSD was seen in $53 \%$ of patients $(n=17)$. Abnormal coronary anatomy was seen in 3 patients $(9 \%)$. Eighteen patients had palliative procedures before aortic root translocation, most commonly a modified Blalock-Taussig shunt $(16,50 \%)$ or a bidirectional Glenn shunt $(3,9 \%)$.

\section{Operative Characteristics}

The operative details are summarized in Table 2. A valved RV-PA conduit was used in 26 patients (81\%): 19 with an aortic homograft (mean conduit size: $15.7 \pm 3.7$ $\mathrm{mm}), 4$ with a pulmonary homograft (mean conduit size $21 \mathrm{~mm}$ ), 2 with a bovine internal jugular vein conduit (Contegra; Medtronic Inc, Minneapolis, Minn), and 1 with the native pulmonary root. A nonvalved transannular patch was used in 6 patients (19\%). An atrial baffle Mustard procedure was performed in 5 patients in the setting of anatomic repair of congenitally corrected TGA. Some of these patients have been reported. ${ }^{14,15}$ Additional procedures are detailed in Table 2.

\section{Early Outcome}

Early outcomes are summarized in Table 3. Thirteen patients were left with an open chest $(41 \%)$, and 2 patients 
TABLE 1. Baseline patient characteristics

\begin{tabular}{|c|c|c|c|c|}
\hline Baseline characteristic & Total population & Valved conduit & Transannular patch & $P$ value \\
\hline No. of patients & 32 & $26(81.3 \%)$ & $6(18.8 \%)$ & \\
\hline Age (mo) & $7.5(16 \mathrm{~d}$ to $42 \mathrm{y})$ & $6.5(16 \mathrm{~d}$ to $42 \mathrm{y})$ & $8.5(5-60)$ & .43 \\
\hline Male patients & $22(68.8 \%)$ & $16(61.5 \%)$ & $6(100 \%)$ & .14 \\
\hline Body weight $(\mathrm{kg})$ & $7.7(2.1-48.8)$ & $6.9(2.1-48.8)$ & $10.1(4.7-17)$ & .24 \\
\hline Body surface area $\left(\mathrm{m}^{2}\right)$ & $0.39(0.17-1.46)$ & $0.37(0.17-1.46)$ & $0.46(0.28-0.69)$ & .26 \\
\hline Diagnosis & & & & .83 \\
\hline D-TGA/VSD/PS & $17(53 \%)$ & $13(50 \%)$ & $4(66.7 \%)$ & \\
\hline DORV/VSD/PS & $10(31 \%)$ & $9(34.6 \%)$ & $1(16.7 \%)$ & \\
\hline L-TGA/VSD/PS & $5(16 \%)$ & $4(14.5 \%)$ & $1(16.7 \%)$ & \\
\hline Previous palliation & $19(59.4 \%)$ & $15(57.7 \%)$ & $4(66.7 \%)$ & $>.99$ \\
\hline mBTS & $16(50 \%)$ & $12(46.2 \%)$ & $4(66.7 \%)$ & .65 \\
\hline Bidirectional Glenn & $3(9.4 \%)$ & $2(7.7 \%)$ & $1(16.7 \%)$ & .48 \\
\hline Pulmonary artery band & $2(6.3 \%)$ & $1(3.8 \%)$ & $1(16.7 \%)$ & .35 \\
\hline Mean LVOT gradient $(\mathrm{mm} \mathrm{Hg})$ & $60.5 \pm 22.3$ & $60.8 \pm 24.3$ & $59.2 \pm 11.1$ & .79 \\
\hline \multicolumn{5}{|l|}{ Coronary anatomy } \\
\hline Normal (or usual for TGA) & $29(90.6 \%)$ & $24(92.3 \%)$ & $5(83.3 \%)$ & .48 \\
\hline Abnormal & $3(9.4 \%)$ & $2(7.7 \%)$ & $1(16.7 \%)$ & .48 \\
\hline Left circumflex from RCA & $2(6.3 \%)$ & $1(3.8 \%)$ & $1(16.7 \%)$ & .35 \\
\hline Inverted origin of coronaries & $1(3 \%)$ & $1(3.8 \%)$ & $0(0 \%)$ & $>.99$ \\
\hline \multicolumn{5}{|l|}{ Associated lesions } \\
\hline Multiple VSDs & $4(12.5 \%)$ & $2(7.7 \%)$ & $2(33.3 \%)$ & .15 \\
\hline Complete common atrioventricular canal defect & $2(6.3 \%)$ & $1(3.8 \%)$ & $1(16.7 \%)$ & .35 \\
\hline Dextrocardia & $3(9.4 \%)$ & $2(7.7 \%)$ & $1(16.7 \%)$ & .38 \\
\hline Situs inversus & $2(6.3 \%)$ & $2(7.7 \%)$ & $0(0 \%)$ & $>.99$ \\
\hline Heterotaxy syndrome & $2(6 \%)$ & $1(3.8 \%)$ & $1(16.7 \%)$ & .35 \\
\hline Parachute mitral valve & $1(3 \%)$ & $1(3.8 \%)$ & $0(0 \%)$ & $>.99$ \\
\hline
\end{tabular}

All values are reported as mean \pm standard deviation, median (range) or number (percentage) unless otherwise noted. DORV, Double outlet right ventricle; $D$-TGA, dextrotransposition of the great arteries; L-TGA, levo-transposition of the great arteries; LVOT, left ventricular outflow tract; $m B T S$, modified Blalock-Taussig shunt; PS, pulmonic stenosis; $R C A$, right coronary artery; $T G A$, transposition of the great arteries; $V S D$, ventricular septal defect.

required reexploration for bleeding $(6.3 \%)$. No patients required extracorporeal membrane oxygenation support. There was 1 early death $(3.1 \%)$ in an 8 -month-old child with heterotaxy syndrome, dextrocardia, congenitally corrected TGA with complete atrio-VSD, and borderline right ventricle hypoplasia. The child underwent anatomic repair (Mustard atrial switch, double patch repair of atrio-VSD, aortic root translocation, and transannular patch for the RVOT reconstruction). Peripheral branch pulmonary artery stenosis with severe pulmonary regurgitation and tricuspid regurgitation developed in the patient, and he underwent early reoperation to place an RV-PA conduit (16-mm Contegra) and tricuspid valve repair. Tricuspid stenosis developed after the reoperation, and he subsequently underwent tricuspid valve replacement with surgical melody valve insertion, ${ }^{16,17}$ dilated up to $19 \mathrm{~mm}$. Gramnegative septicemia and multiorgan failure developed, and the patient died on postoperative day 64 .

Three patients required early reoperation $(9.3 \%), 1$ of whom eventually died of septicemia as described earlier. One other patient presented with moderate aortic regurgitation, which was addressed with reduction of the sinotubular junction, aortic valve commissuroplasty, along with closure of a residual VSD. Another patient had a Mustard baffle leak repaired. Two additional patients required early reinterventions in the catheterization laboratory $(6.3 \%), 1$ for superior vena cava stenting for superior vena cava stenosis and 1 for device closure of Mustard baffle leak.

On predischarge echocardiogram, 1 patient had more than mild LVOTO (3.1\%), with a 20 -mm peak gradient across the LVOT. Residual RVOTO was observed in 8 patients $(25 \%)$, of whom 7 had an RV-PA conduit and 1 had transannular patch. One patient had moderate aortic insufficiency $(3.1 \%)$. Two patients had LV dysfunction without any evidence of coronary ischemia at the time of discharge. A hemodynamically nonsignificant residual VSD occurred in 16 patients $(50 \%)$.

\section{Follow-up}

Among the 31 survivors, the median follow-up was 20.8 months (range, 1 month to 16.5 years). There were no late deaths during follow-up. Good functional capacity was seen in all but 1 patient $(96 \%$ of patients in New York Heart Association class I or II). Kaplan-Meier estimates of survival are illustrated in Figure 1.

A total of 14 patients ( $45.2 \%$ of survivors) required a reintervention during follow-up. Catheter-based reinterventions 
TABLE 2. Operative details

\begin{tabular}{|c|c|c|c|c|}
\hline Operative characteristic & Entire sample ( $N=32)$ & Valved conduit $(n=26)$ & Transannular patch $(n=6)$ & $P$ value \\
\hline CPB (min) & $265.3 \pm 76.9$ & $266.5 \pm 84.9$ & $260.2 \pm 23.5$ & .56 \\
\hline Aortic crossclamp (min) & $134 \pm 52$ & $141.9 \pm 45.7$ & $99.8 \pm 62.9$ & .14 \\
\hline Fibrillatory arrest time (min) & $81.7 \pm 60.2$ & $77.2 \pm 60.3$ & $102 \pm 77.8$ & .73 \\
\hline LeCompte maneuver & $31(96.9 \%)$ & $25(96.2 \%)$ & $6(100 \%)$ & $>.99$ \\
\hline \multicolumn{5}{|l|}{ RVOT reconstruction } \\
\hline Valved RV-PA conduit & $26(81 \%)$ & - & - & - \\
\hline Transannular patch & $6(19 \%)$ & - & - & - \\
\hline \multicolumn{5}{|l|}{ Management of coronaries } \\
\hline Full coronary reimplantation & $18(56.3 \%)$ & $17(65.4 \%)$ & $1(16.7 \%)$ & .06 \\
\hline Partial coronary reimplantation & $1(3.1 \%)$ & $1(3.8 \%)$ & $0(0 \%)$ & $>.99$ \\
\hline Intact coronaries & $13(40.6 \%)$ & $8(30.8 \%)$ & $5(83.3 \%)$ & .03 \\
\hline Root translocation on a beating heart & $6(18.8 \%)$ & $3(11.5)$ & $3(50 \%)$ & .06 \\
\hline \multicolumn{5}{|l|}{ Additional procedure } \\
\hline Mustard procedure & $5(15.6 \%)$ & $4(15.4 \%)$ & $1(16.7 \%)$ & $>.99$ \\
\hline Pulmonary artery plasty & $5(15.6 \%)$ & $4(15.4 \%)$ & $1(16.7 \%)$ & $>.99$ \\
\hline Mitral valvuloplasty & $4(12.5 \%)$ & $4(15.4 \%)$ & $0(0 \%)$ & .57 \\
\hline Multiple VSD closure & $5(15.6 \%)$ & $3(11.5 \%)$ & $2(33.3 \%)$ & .23 \\
\hline Tricuspid valve repair & $3(9.4 \%)$ & $2(7.7 \%)$ & $1(16.7 \%)$ & .48 \\
\hline Glenn takedown & $3(9.4 \%)$ & $2(7.7 \%)$ & $1(16.7 \%)$ & .48 \\
\hline Complete common atrioventricular canal repair & $2(6.3 \%)$ & $1(3.8 \%)$ & $1(16.7 \%)$ & .35 \\
\hline Pacemaker implantation & $1(3.1 \%)$ & $1(3.8 \%)$ & $0(0 \%)$ & $>.99$ \\
\hline Enlargement of VSD & $1(3.1 \%)$ & $1(3.8 \%)$ & $0(0 \%)$ & $>.99$ \\
\hline Anomalous pulmonary venous return repair & $1(3.1 \%)$ & $1(3.8 \%)$ & $0(0 \%)$ & $>.99$ \\
\hline
\end{tabular}

All values are reported as mean \pm standard deviation, median (range) or number (percentage) unless otherwise noted. $C P B$, Cardiopulmonary bypass; $R V O T$, right ventricular outflow tract; $R V-P A$, right ventricular to pulmonary artery; $V S D$, ventricular septal defect.

occurred in 10 patients $(32.3 \%)$, which included RV-PA conduit dilatation or stent placement in 5 patients $(16.1 \%)$, balloon dilatation of branch pulmonary arteries with or without stent placement in 4 patients $(12.9 \%)$, ASD closure in 2 patients $(6.5 \%)$, and tricuspid valve balloon dilatation in 1 patient $(3.2 \%)$. Among these patients with catheterbased reinterventions, 9 had a valved RV-PA conduit $(34.6 \%)$ and 1 had transannular patch $(20 \%, P>.99)$.

Six patients (19.4\%) required surgical reoperation, all of whom had valved RV-PA conduits. Surgery included RV-PA conduit change in 3 patients, Melody valve (Medtronic Inc) replacement in the RVOT position in 1 patient, tricuspid valve repair and conversion of valved RV-PA conduit to transannular patch in 1 patient, and mitral and tricuspid valve repair with pulmonary valve replacement in 1 patient. There were no perioperative deaths for these reoperations. Two of these patients required a second reoperation, for RV-PA conduit re-replacement with aortic valve repair and right coronary ostium unroofing in 1 patient and for mitral valve replacement with a $19-\mathrm{mm}$ St Jude Inc (St Paul, Minn) mechanical prosthesis and tricuspid valve repair in 1 patient. Overall freedom from reintervention is illustrated in Figure 2. There was not a significant difference when stratified by transannular patch versus RV-PA conduit (log-rank test, $P=.91$; data not shown). Freedom from reintervention on the RV-PA connection is illustrated in Figure 3 and was better in patients with a transannular patch (no reinterventions), although not to a statistically significant level $(P=.34)$. The overall echocardiographic results at latest follow-up are summarized in Table 4.

\section{DISCUSSION}

Our study focuses on the early and midterm results of aortic root translocation and the impact of type of RVOT reconstruction. It expands on our previous experience ${ }^{11}$ in managing patients with D-TGA/VSD/PS who underwent anatomic repair with aortic root translocation. We report on 32 patients by grouping them by management of the RVOT; 26 patients had a valved RV-PA conduit, and 6 patients had a transannular patch with direct approximation of the pulmonary bifurcation to the RVOT and anterior patch enlargement. ${ }^{18-20}$ Reinterventions and reoperations were more frequent in patients with a valved conduit. During a late follow-up extending to 16.5 years, no patients showed LV dysfunction, 2 patients presented moderate aortic insufficiency, 1 patient had aortic valvuloplasty at the time of RV-PA conduit replacement, and no patients presented residual LVOTO. Two patients (1 in each group) presented with mild coronary compression.

Aortic translocation is a technically demanding operation, with risks of destabilizing the aortic valve or kinking/compressing the proximal coronary arteries. In the Toronto experience, coronary anomalies were the principal reason for favoring a Rastelli procedure. ${ }^{21}$ The 
TABLE 3. Early outcomes

\begin{tabular}{|c|c|c|c|c|}
\hline Outcome variables & Entire sample $(\mathbf{N}=32)$ & Valved conduit $(n=26)$ & Transannular patch $(n=6)$ & $P$ value \\
\hline Hospital stay (d) & $13(8-64)$ & $14(8-49)$ & $11(8-64)$ & .87 \\
\hline CICU stay (d) & $6(2-64)$ & $6.5(2-19)$ & $5.5(2-64)$ & .82 \\
\hline LVOTO & $1(3 \%)$ & $1(3.8 \%)$ & $0(0 \%)$ & $>.99$ \\
\hline LVOT peak gradient (mm Hg) & $0.9 \pm 3.9$ & $1.14 \pm 4.32$ & * & \\
\hline RVOTO & $8(25 \%)$ & $7(26.9 \%)$ & $1(16.7 \%)$ & $>.99$ \\
\hline RVOT peak gradient (mm Hg) & $6.1 \pm 11.6$ & $6.4 \pm 11.6$ & $5 \pm 12.2$ & .87 \\
\hline Aortic insufficiency & & & & $>.99$ \\
\hline None & $24(75 \%)$ & $19(73.1 \%)$ & $5(83.3 \%)$ & \\
\hline Mild & $7(21.9 \%)$ & $6(23.1 \%)$ & $1(16.7 \%)$ & \\
\hline Moderate & $1(3.1 \%)$ & $1(3.8 \%)$ & $0(0 \%)$ & \\
\hline $\begin{array}{l}\text { Mild to moderate mitral } \\
\text { regurgitation }\end{array}$ & $1(3.1 \%)$ & $1(3.8 \%)$ & $0(0 \%)$ & $>.99$ \\
\hline $\begin{array}{l}\text { Mild to moderate LV } \\
\text { dysfunction }\end{array}$ & $2(6.3 \%)$ & $1(3.8 \%)$ & $1(16.7 \%)$ & .35 \\
\hline Residual VSD $\dagger$ & $16(50 \%)$ & $12(46.2 \%)$ & $4(66.7 \%)$ & .65 \\
\hline Complete heart block & $4(12.5 \%)$ & $3(11.5 \%)$ & $1(16.7 \%)$ & $>.99$ \\
\hline Early reoperation & $3(9.4 \%)$ & $2(7.7 \%)$ & $1(16.7 \%)$ & .48 \\
\hline Early mortality & $1(3.1 \%)$ & $0(0 \%)$ & $1(16.7 \%)$ & .19 \\
\hline
\end{tabular}

All values are reported as mean \pm standard deviation, median (range), or number (\%) unless otherwise noted. $C I C U$, Cardiac intensive care unit; $L V$, left ventricular; $L V O T$, left ventricular outflow tract; $L V O T O$, left ventricular outflow tract obstruction; $R V O T$, right ventricular outflow tract; $R V O T O$, right ventricular outflow tract obstruction; VSD, ventricular septal defect. *Too few measures for a meaningful mean. $\dagger$ Residual VSD was defined on the basis of perioperative echocardiography irrespective of size. All patients had $\mathrm{Q}_{\mathrm{P}}: \mathrm{Q}_{\mathrm{S}}$ less than 1:1.5, the VSDs were hemodynamically insignificant, and no patient required reoperation for residual VSD.

ASO with LVOTO resection is associated with a high rate of aortic insufficiency and reoperations on the aortic valve, ${ }^{1}$ although repair is possible with excellent results, ${ }^{22-26}$ and REV or Rastelli procedures are associated with a $10 \%$ rate of reoperation for LVOTO at 10 years. ${ }^{1,3,8}$

There is great debate on how and when to choose which surgical management option in patients with D-TGA/VSD/ PS: ASO with LVOT resection, REV, Rastelli, or aortic root translocation..$^{1,13,21,27}$ Yeh and colleagues ${ }^{8}$ recently reviewed the available studies on these different approaches, showing that, after taking into account era effects, overall

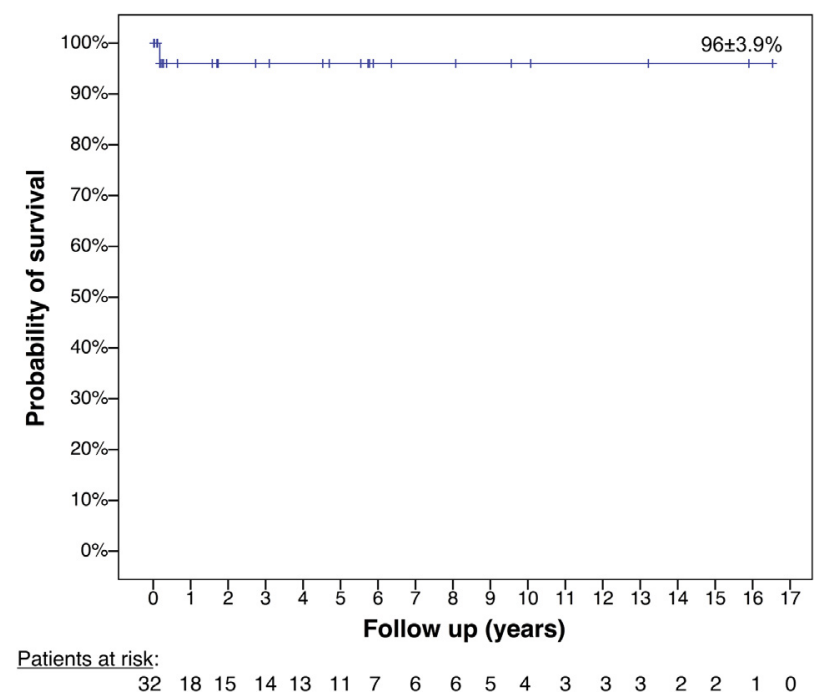

FIGURE 1. Kaplan-Meier survival estimates. survival was not significantly different between management options. Historically, our institutional approach has been to favor ASO and LVOTO resection when possible. However, we have managed a select number of these patients with aortic root translocation. We previously reported our results comparing these different management strategies, showing that patients undergoing the Rastelli procedure were more likely to require surgical reintervention for LVOTO than other groups $(P=.015)$, particularly in patients with a higher pulmonary valve $Z$ score $(P=.012)$.

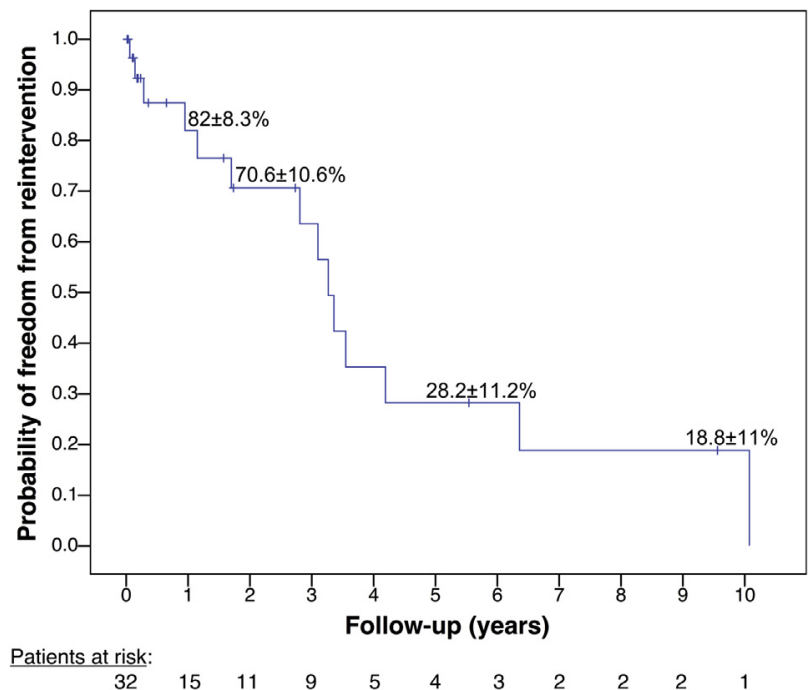

FIGURE 2. Kaplan-Meier estimates of freedom from reintervention among survivors. 


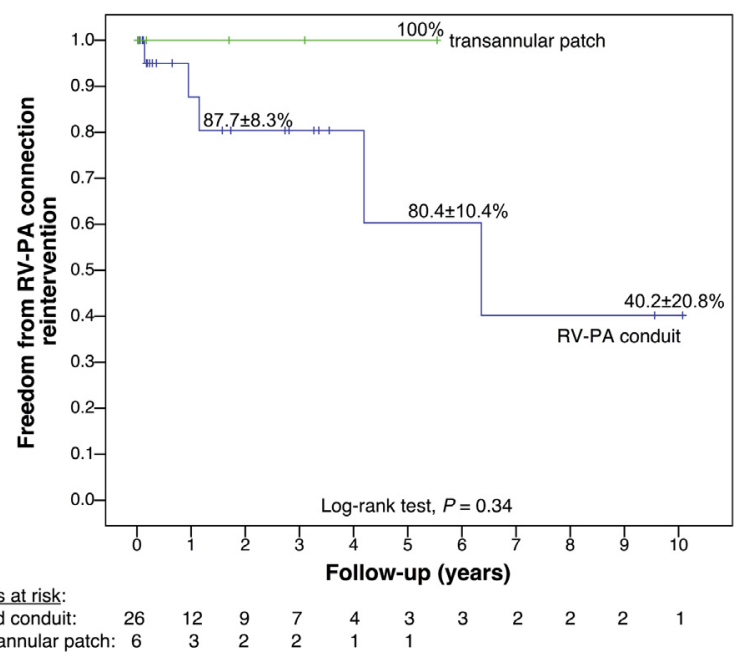

FIGURE 3. Kaplan-Meier estimates of freedom from RV-PA connection reintervention stratified by connection type. $R V-P A$, Right ventricle to pulmonary artery.

The larger pulmonary valve created a longer intracardiac baffle at higher risk of obstruction. By comparison, in the patients reported in this article, 1 patient $(3.1 \%)$ showed a peak LVOT gradient of $20 \mathrm{~mm} \mathrm{Hg}$ at discharge, and no patients showed LVOTO at late follow-up.
In perhaps one of the most interesting comparative studies on the subject, Hazekamp and colleagues ${ }^{28}$ studied 33 patients with LVOTO in various forms of transposition, of whom 21 had TGA/VSD/PS. ${ }^{28}$ They found that ASO and LVOT muscle resection was feasible in 10 of 21 patients $(47 \%)$. Aortic root translocation or Rastelli was indicated in 9 patients $(42 \%)$, in whom the authors determined that the Nikaidoh procedure could be performed in 8 of the 9 patients, because 1 patient was not favorable for aortic root translocation, with a large aortic valve, very small LVOT, and large membranous anterior subaortic VSD, which could be more easily repaired with a Rastelli baffle, because root translocation would not provide any significant benefit, because it would be done over a very short distance.

More recently, Honjo and colleagues ${ }^{21}$ from the Toronto group tried to derive retrospectively an anatomic "LVOT complexity score" to help in choosing between management options. Although interesting, this complexity score, derived retrospectively on patients whose management was decided traditionally (ie, by preoperative echocardiographic and surgical inspection), would seem to confirm that this esteemed and established program, with no early deaths in their experience, chose the right option for the right patient, with higher LVOT complexity scores in patients with a Nikaidoh

TABLE 4. Follow-up evaluation

\begin{tabular}{|c|c|c|c|c|}
\hline Follow-up variable & Value & Valved conduit $(\mathrm{n}=26)^{*}$ & Transannular patch $(\mathbf{n}=5) *$ & $P$ value \\
\hline Follow-up duration (mo) & $20.8(1 \mathrm{wk}$ to $16.5 \mathrm{y})$ & $26.8(1 \mathrm{wk}$ to $16.5 \mathrm{y})$ & $20.4(2 \mathrm{wk}$ to $5.5 \mathrm{y})$ & .36 \\
\hline LV ejection fraction & $60.2 \pm 5.9$ & $59.9 \pm 6.1$ & $62.3 \pm 4$ & .54 \\
\hline RV function & & & & $>.99$ \\
\hline Normal & $25(89.3 \%)$ & $22(88 \%)$ & $3(100 \%)$ & \\
\hline Mildly reduced & $2(7.1 \%)$ & $2(8 \%)$ & $0(0 \%)$ & \\
\hline Moderately reduced & $1(3.6 \%)$ & $1(4 \%)$ & $0(0 \%)$ & \\
\hline RVOTO & $10(35.7 \%)$ & $9(36 \%)$ & $1(33.3 \%)$ & $>.99$ \\
\hline Mean RVOT peak gradient (mm Hg) & $9.0 \pm 14.2$ & $9.3 \pm 14.7$ & $6.7 \pm 11.5$ & .81 \\
\hline LVOTO & $0(0 \%)$ & $0(0 \%)$ & $0(0 \%)$ & $>.99$ \\
\hline Aortic insufficiency & & & & .64 \\
\hline None-trivial & $12(46.2 \%)$ & $10(43.5 \%)$ & $2(66.7 \%)$ & \\
\hline Mild & $13(50 \%)$ & $12(52.2 \%)$ & $1(33.3 \%)$ & \\
\hline Moderate & $1(3.8 \%)$ & $1(4.3 \%)$ & $0(0 \%)$ & \\
\hline RV-PA conduit regurgitation & & & & .64 \\
\hline None-trivial & $12(42.9 \%)$ & $10(41.7 \%)$ & $2(50 \%)$ & \\
\hline Mild & $7(25 \%)$ & $6(25 \%)$ & $1(25 \%)$ & \\
\hline Moderate & $6(21.4 \%)$ & $6(25 \%)$ & $0(0 \%)$ & \\
\hline Severe & $3(10.7 \%)$ & $2(8.3 \%)$ & $1(25 \%)$ & \\
\hline Coronary compression & $1(3.8 \%)$ & $1(4.3 \%)$ & $0(0 \%)$ & $>.99$ \\
\hline Mitral insufficiency & & & & $>.99$ \\
\hline None-mild & $30(96.8 \%)$ & $25(96.2 \%)$ & $5(100 \%)$ & \\
\hline Moderate & $1(3.2 \%)$ & $1(3.8 \%)$ & $0(100 \%)$ & \\
\hline Tricuspid valve insufficiency & & & & $>.99$ \\
\hline None-trivial & $9(33.3 \%)$ & $8(33.3 \%)$ & $1(33.3 \%)$ & \\
\hline Mild & $17(63 \%)$ & $15(62.5 \%)$ & $2(66.7 \%)$ & \\
\hline Moderate & $1(3.7 \%)$ & $1(4.2 \%)$ & $0(0 \%)$ & \\
\hline
\end{tabular}

Variables are presented as mean \pm standard deviation, median (range), and number (percentage of survivors). $L V$, Left ventricular; $R V$, right ventricular; $R V O T$, right ventricular outflow tract; RVOTO, right ventricular outflow tract obstruction; RV-PA, right ventricle-pulmonary artery; LVOTO, left ventricular outflow tract obstruction. *Not all echocardiographic parameters were available on follow-up echocardiogram. 
procedure than in patients with an $\operatorname{ASO}(P=.019)$. However, no thresholds of LVOT complexity score were determined to help in choosing management, likely because of the sample size, and it remains to be seen if this LVOT complexity score can be useful in the clinical management of patients in a prospective application of a management protocol based on these scores.

\section{Study Limitations}

First, it is a retrospective, single-center, noninterventional study designed to evaluate the outcomes of an established clinical program. All patients were managed as individuals and not according to a treatment protocol, which would have improved our ability to analyze outcomes. Our analyses were limited by the small patient sample, even if this represents one of the largest populations of aortic translocation procedures. Furthermore, the finding of fewer interventions in the transannular patch group may be an artifact of age at repair or duration of follow-up. Finally, the follow-up, although extending to 16.5 years, was limited to a median of just less than 2 years, because a large proportion of the patients underwent operation more recently.

\section{CONCLUSIONS}

Aortic root translocation can be performed with low early and late mortality, with extended operative times. There was preserved aortic valve function and no LVOTO at late follow-up. The use of a transannular patch had early outcomes comparable to valved conduits, with a trend for fewer late reoperations during follow-up.

\section{References}

1. Emani SM, Beroukhim R, Zurakowski D, Pigula FA, Mayer JE, del Nido PJ, et al. Outcomes after anatomic repair for d-transposition of the great arteries with left ventricular outflow tract obstruction. Circulation. 2009;120(11 Suppl):S53-8.

2. Wernovsky G, Jonas RA, Colan SD, Sanders SP, Wessel DL, Castanñeda AR, et al. Results of the arterial switch operation in patients with transposition of the great arteries and abnormalities of the mitral valve or left ventricular outflow tract. J Am Coll Cardiol. 1990;16:1446-54.

3. Kreutzer C, De Vive J, Oppido G, et al. Twenty-five-year experience with Rastelli repair for transposition of the great arteries. J Thorac Cardiovasc Surg. 2000; 120:211-23.

4. Dearani JA, Danielson GK, Puga FJ, Mair DD, Schleck CD. Late results of the Rastelli operation for transposition of the great arteries. Semin Thorac Cardiovasc Surg Pediatr Card Surg Annu. 2001;4:3-15.

5. Di Carlo D, Tomasco B, Cohen L, Vouhe P, Lecompte Y. Long-term results of the REV (reparation a l'etage ventriculaire) operation. J Thorac Cardiovasc Surg. 2011;142:336-43

6. Lecompte Y, Neveux JY, Leca F, Zannini L, Tu TV, Duboys Y, et al. Reconstruction of the pulmonary outflow tract without prosthetic conduit. J Thorac Cardiovasc Surg. 1982;84:727-33.

7. Lecompte Y, Zannini L, Hazan E, Jarreau MM, Bex JP, Tu TV, et al. Anatomic correction of transposition of the great arteries. J Thorac Cardiovasc Surg. 1981; 82:629-31.

8. Yeh T Jr, Ramaciotti C, Leonard SR, Roy L, Nikaidoh H. The aortic translocation (Nikaidoh) procedure: midterm results superior to the Rastelli procedure. J Thorac Cardiovasc Surg. 2007;133:461-9.
9. Bex JP, Lecompte Y, Baillot F, Hazan E. Anatomical correction of transposition of the great arteries. Ann Thorac Surg. 1980;29:86-8.

10. Nikaidoh H. Aortic translocation and biventricular outflow tract reconstruction A new surgical repair for transposition of the great arteries associated with ventricular septal defect and pulmonary stenosis. J Thorac Cardiovasc Surg. 1984; 88:365-72.

11. Bautista-Hernandez V, Marx GR, Bacha EA, del Nido PJ. Aortic root translocation plus arterial switch for transposition of the great arteries with left ventricular outflow tract obstruction: intermediate-term results. J Am Coll Cardiol. 2007;49: 485-90.

12. Morell VO, Jacobs JP, Quintessenza JA. Aortic translocation in the management of transposition of the great arteries with ventricular septal defect and pulmonary stenosis: results and follow-up. Ann Thorac Surg. 2005;79: 2089-93.

13. Hu SS, Liu ZG, Li SJ, Shen XD, Wang X, Liu JP, et al. Strategy for biventricular outflow tract reconstruction: Rastelli, REV, or Nikaidoh procedure? J Thorac Cardiovasc Surg. 2008;135:331-8.

14. Bautista-Hernandez V, Myers PO, Cecchin F, Marx GR, Del Nido PJ. Late left ventricular dysfunction after anatomic repair of congenitally corrected transposition of the great arteries. J Thorac Cardiovasc Surg. 2014;148: 254-8.

15. Myers PO, Bautista-Hernandez V, Baird CW, Emani SM, Marx GR, Del Nido PJ. Tricuspid regurgitation or Ebsteinoid dysplasia of the tricuspid valve in congenitally corrected transposition: is valvuloplasty necessary at anatomic repair? J Thorac Cardiovasc Surg. 2014;147:576-80.

16. Abdullah I, Ramirez FB, McElhinney DB, Lock JE, del Nido PJ, Emani S. Modification of a stented bovine jugular vein conduit (melody valve) for surgical mitral valve replacement. Ann Thorac Surg. 2012;94:e97-8.

17. Quinonez LG, Breitbart R, Tworetsky W, Lock JE, Marshall AC, Emani SM Stented bovine jugular vein graft (Melody valve) for surgical mitral valve replacement in infants and children. J Thorac Cardiovasc Surg. 2014;148:1443-9.

18. Sakamoto K, Ota N, Murata M, et al. Modified Nikaidoh procedure with double-root translocation in a 1-year-old boy. Ann Thorac Surg. 2014;97: 1055-7.

19. Hu SS, Li SJ, Wang X, Wang LQ, Xiong H, Li LH, et al. Pulmonary and aortic root translocation in the management of transposition of the great arteries with ventricular septal defect and left ventricular outflow tract obstruction. $J$ Thorac Cardiovasc Surg. 2007;133:1090-2.

20. Mair R, Sames-Dolzer E, Vondrys D, Lechner E, Tulzer G. En bloc rotation of the truncus arteriosus-an option for anatomic repair of transposition of the great arteries, ventricular septal defect, and left ventricular outflow tract obstruction. J Thorac Cardiovasc Surg. 2006;131:740-1.

21. Honjo O, Kotani Y, Bharucha T, Mertens L, Caldarone CA, Redington AN et al. Anatomical factors determining surgical decision-making in patients with transposition of the great arteries with left ventricular outflow tract obstruction. Eur J Cardiothorac Surg. 2013;44:1085-94.

22. Baird CW, Myers PO, Del Nido PJ. Aortic valve reconstruction in the young infants and children. Semin Thorac Cardiovasc Surg Pediatr Card Surg Annu. 2012;15:9-19.

23. Myers PO, Tissot C, Christenson JT, Cikirikcioglu M, Aggoun Y, Kalangos A. Aortic valve repair by cusp extension for rheumatic aortic insufficiency in children: long-term results and impact of extension material. J Thorac Cardiovasc Surg. 2010;140:836-44.

24. Bacha EA, McElhinney DB, Guleserian KJ, et al. Surgical aortic valvuloplasty in children and adolescents with aortic regurgitation: acute and intermediate effects on aortic valve function and left ventricular dimensions. J Thorac Cardiovasc Surg. 2008;135:552-9. 9 e1-3.

25. Myers PO, Del Nido PJ, Emani SM, Marx GR, Baird CW. Valve-sparing aortic root replacement and remodeling with complex aortic valve reconstruction in children and young adults with moderate or severe aortic regurgitation. $J$ Thorac Cardiovasc Surg. 2014;147:1768-76.

26. d'Udekem Y, Siddiqui J, Seaman CS, Konstantinov IE, Galati JC, Cheung MM et al. Long-term results of a strategy of aortic valve repair in the pediatric population. J Thorac Cardiovasc Surg. 2013;145:461-9.

27. Pretre R. Editorial comment: Arterial switch, reparation a l'etage ventriculaire, Rastelli or Nikaidoh? Eur J Cardiothorac Surg. 2013;44:1094-5.

28. Hazekamp M, Portela F, Bartelings M. The optimal procedure for the great arteries and left ventricular outflow tract obstruction. An anatomical study. Eur J Cardiothorac Surg. 2007;31:879-87. 